\title{
Optimizing Consumption and Emission in Gas Fuel Consuming Power Applying DEA Model
}

\author{
Samaneh Shokravi ${ }^{1}$ \\ S.F. Ghaderi ${ }^{2}$ \\ ${ }^{2}$ Research Institute of Energy Management and Planning and \\ 1,2 Department of Industrial Engineering, Faculty of Engineering, University of Tehran \\ P.O. Box 11365 Tehran, IRAN
}

samans83@yahoo.com

Ghaderi@ut.ac.ir

\begin{abstract}
.
In this paper, energy consumption and carbon dioxide emission of the Iran gas generators is studied using Data Envelopment Analysis (DEA) and Goal Programming (GP) to show the importance of $\mathrm{CO}_{2}$ emission in Iran like most other countries and also conserve fuel as key role of today life and industry. Ramanathan studied energy consumption and carbon dioxide emission as well, from 17 countries of the Middle East and North Africa (MENA) with four indicators for the year 1996. In this paper a simple goal programming model to minimizing carbon dioxide emission and gas consumption is revealed for the year 2004 by employing three main indicators.

First electricity generated by generators, then carbon dioxide emission and at last natural gas consumption as fuel. Albeit there are other factors like generators condition, environmental situation and etc, that could be considered for further studies. The analysis concludes the most and least efficient units and revealed an optimizing model which its optimized results are comparable to international standards for $\mathrm{CO}_{2}$ emission and fuel consumption.
\end{abstract}

\section{Key words}

Carbon dioxide emission, Data Envelopment Analysis (DEA), Energy consumption, Goal programming.

\section{Introduction}

In this era more than ever various kind of energy are important for life and industry, one of these kinds is electricity which is made by different kind of fuel, although, in compare to 2003 in 2004 use of gas, wind and water energies as a fuel for generators had increased and made Iran independent in top ten of whole world, however, minimizing the cost and optimizing the use of fuel according to their greenhouse gas emission as a demolition cost are still a goal to achieve.

Energy consumption and carbon dioxide emissions of the world are increasing at alarming rates. Continued carbon dioxide emissions are likely to lead to catastrophic problems such as the greenhouse effect. $\mathrm{CO}_{2}$ emissions are driven by several factors, the most prominent being energy consumption from fossil fuels and the level of economic activity. Hence, efforts have been made to analyze the energy consumption and $\mathrm{CO}_{2}$ emissions in Iran.
Patterns in the level of energy consumption, economic activity and $\mathrm{CO}_{2}$ emissions of many countries of the world have been analyzed in the literature. Ramanathan [1] provided substantial analysis of energy consumption and $\mathrm{CO}_{2}$ of the countries of the Middle East and North Africa (MENA), using Data Envelopment Analysis and Malmquist Productivity index approach for the period of 1992-1996.Pao [2] used linear and nonlinear statistical models, including artificial neural network (ANN) methods, to investigate the influence of the four economic factors, which were the national income (NI), population (POP), gross of domestic production (GDP), and consumer price index (CPI), on the electricity consumption in Taiwan and then to develop an economic forecasting model. This paper attempts to provide analysis for fuel consumption and $\mathrm{CO}_{2}$ emissions of gas generators of Iran using Data Envelopment Analysis and Goal Programming. Green house emissions by gas generators in 2004 for $\mathrm{NO}_{\mathrm{x}}$ were $11.8 \%$, for $\mathrm{SO}_{2}, 17.3 \%$, for $\mathrm{CO}_{2} 25.3 \%$, etc. So on account of the highest one is $\mathrm{CO}_{2}$ that made the model which is simply extendable for the others.

Based on World Wide Bank and Environment Organization information demolition cost $\mathrm{CO}_{2}$ is about 2176 million dollar, with this amount of money we could have significant raise in the industry.

\section{DEMOLITION COST}

A direct cost of environmental effects, such as destroying ecosystem and hygiene effects on people, called demolition cost. In fact, this cost is revealed harmful effects of pollution or a mission on products, ecosystem, and human health that often is an exterior parameter which not counts in pricing. To calculate harm caused by polluted emissions, effects of them should be quantified.

Demolition cost by the name of "Social Cost" is presented by World Wide Bank and Environment Organization studies which based on America EPA coefficients in table I. 


\begin{tabular}{lc}
\hline Parts & $\begin{array}{c}\mathrm{CO}_{2} \\
\text { (Mton) }\end{array}$ \\
\hline Based on World Wide Bank & \\
And Environment Organization: & 2574 \\
\hline General, business and house & 1240 \\
Industries & 2333 \\
Transportation & 236 \\
Agricultural & 2176 \\
Generators & 8559 \\
All & \\
\hline Based on America EPA coefficients: & 17157 \\
\hline Business and houses & 8267 \\
Industries & 15554 \\
Transportation & 1571 \\
Agricultural & 14507 \\
Generators & 57056 \\
\hline All
\end{tabular}

\section{MODELING}

\section{A Reason of choosing gas generators in this paper}

Choosing appropriate fuel for generators in order to economic criteria such as fuel cost, geographical regions of generators, availability, environmental pollution of fuel, even long and short term policies have special importance, Hence system and fuel modification could reduce environmental pollution as well as production cost.

In recent years use of gas fuel boost and based on year report of 2004, by replacing gas fuel in national range, three million dollars was saved. Natural gas in compare to other fuels is a clean one and has the minimum pollution emissions rate, although, $46.9 \%$ of $\mathrm{CO}_{2}$ emissions is belong to gas fuel. Under the auspices of minimizing the pollution of generators with the cleanest fuel it may possible to present new approach for energy segment of Iran.

\section{B GP Model}

First we introduce parameters and variables are used in models:

$\mathrm{S}_{\mathrm{i}}$ : deviation variable from goal limit

$\mathrm{X}_{\mathrm{CO} 2}$ : Carbon dioxide emission (Mton)

$\mathrm{X}_{\text {elec }}$ : electricity generated by generators in 2004 (MKwh)

$\mathrm{Y}_{\text {fuel }}$ : gas consumption as a generators fuel $\left(\mathrm{m}^{3}\right)$

$\mathrm{U}$ : demolition cost estimated by international bank and environment ministry for $\mathrm{CO}_{2}$ emission generators in 2004 (the coefficient of $15.03 \%$ is because we evaluate demolition cost according to percentage of total product) $\mathrm{P}_{\mathrm{i}}$ : Weight according to importance of goal (P1>P2>P3) A: Total electricity production in country in 2004 (which was $166917 \times 10^{6} \mathrm{KWh}$ that we trying to aimed higher so we replaced it with a higher amount)

$\mathrm{B}$ : $\mathrm{CO}_{2}$ emission by gas generators in 2004 (equal to $9067266 \mathrm{~m}^{3}$ )
C: Consumption of natural gas in 2004 (equal to $885 \times 10^{6}$ $\mathrm{m}^{3}$ )

D: Demolition and social cost in 2004 resulted by CO2 pollution (\$)

The presented model tries to achieve explained goals with tools of linear and goal programming. For weighting, DEA is used, that helps to find out the efficient unit and used shadow prices of these units as goal coefficients.

\section{Input and output of energy balance sheet of 2004}

Decision making units, inputs and out puts are revealed in table 2. Since the exact amount of $\mathrm{CO}_{2}$ emissions of every unit is not accessible the approximate amount are considered as production percentage of total electricity generated by these generators.

\section{Data Envelopment Analysis}

Data Envelopment Analysis (DEA) is a methodology based upon an interesting application of linear programming. It has been successfully employed for assessing the relative performance of set firms, usually called Decision-Making Units (DMU), which use a variety of identical inputs to produce a variety of identical outputs. The basic ideas behind DEA back to Farrel, but the recent series of discussions started with the article by Charnes et al. [3]. The Charnes Model denoted as (1):

$$
\begin{aligned}
& \max \frac{\sum_{j=1}^{J} v_{j m} y_{j m}}{\sum_{i=1}^{I} u_{i m} x_{i m}} \\
& \text { subjected to } \\
& 0 \leq \frac{\sum_{j=1}^{J} v_{j m} y_{j n}}{\sum_{i=1}^{I} u_{i m} x_{i n}} \leq 1 ; n=1,2, \ldots, N \\
& v_{j m}, u_{i m} \geq \varepsilon ; i=1,2, \ldots, I ; j=1,2, \ldots, \quad J
\end{aligned}
$$

The Goal Programming model is denoted as (2) and (3):

$$
\begin{aligned}
& \text { subjected to } \\
& x_{1} \geq B \\
& x_{2} \leq A \\
& y_{1} \geq C \\
& x_{1}+x_{2}-y_{1} \leq 0 \\
& U \geq D
\end{aligned}
$$$$
\text { Min } P_{1} S_{3}{ }^{+}+P_{2} S_{1}{ }^{+}+P_{3}\left(S_{2}{ }^{-}+S_{4}^{+}\right)
$$

In result: 
Min $P_{1} S_{3}^{+}+P_{2} S_{1}^{+}+P_{3}\left(S_{2}^{-}+S_{4}^{+}\right)$

subjected to

$x_{1}-S_{1}{ }^{+}+S_{1}^{-}=90.672668$ Mton

$x_{2}+S_{2}{ }^{-}-S_{2}{ }^{+}=1000000 \quad M k w h$

(3)

$y_{1}-S_{3}{ }^{+}+S_{3}^{-}=885 \mathrm{Mm}^{3}$

$x_{1}+x_{2}=y_{1}$

$U-S_{4}^{+}=\frac{15.03}{100} 2176=327.05 \quad$ MRial

DEA aims to minimize the inputs and maximize the outputs, therefore in this paper, $\mathrm{CO}_{2}$ emissions and fuel consumption are inputs and electricity production is output of the model which is shown in table II.

\section{E Efficiency}

DEA found the efficient units which are "Hasa", "yazd C.C.” and "Yazdzanbagh” although technical efficiency of every unit is available in table III.
Table II. Inputs and outputs

\begin{tabular}{|c|c|c|c|c|}
\hline DMUs & $\begin{array}{l}\text { Fuel } \\
(106 \\
\text { m3) }\end{array}$ & $\begin{array}{c}\text { Net } \\
\text { Productio } \\
n(106 \\
k W h)\end{array}$ & $\begin{array}{c}\mathrm{CO} 2 \\
(\%)\end{array}$ & $\begin{array}{c}\text { Percentag } \\
\text { e of total } \\
\text { Productio } \\
\text { n (\%) }\end{array}$ \\
\hline Shiraz & 360.754 & 806.314 & 0.453 & 0.5 \\
\hline Mashhad & 299.789 & 720.352 & 0.408 & 0.45 \\
\hline Loshan & 89.829 & 294.180 & 0.163 & 0.18 \\
\hline Rey & 920.668 & 3159.942 & 1.768 & 1.95 \\
\hline Tabriz & 23.932 & 46.609 & 0.027 & 0.03 \\
\hline Zargan & 124.301 & 311.469 & $\begin{array}{c}0.172 \\
3\end{array}$ & 0.19 \\
\hline Orumieh & 37.201 & 109.212 & 0.063 & 0.07 \\
\hline Shirvan & 87.655 & 197.187 & 0.108 & 0.12 \\
\hline Shariati & 80.182 & 178.766 & 0.099 & 0.11 \\
\hline Sufian & 46.568 & 140.507 & 0.081 & 0.09 \\
\hline Hasa & 7.761 & 42.214 & 0.027 & 0.03 \\
\hline $\begin{array}{l}\text { Shahid } \\
\text { Salimi }\end{array}$ & 362.593 & 101.634 & 0.607 & 0.67 \\
\hline Kazerun & $\begin{array}{c}1405.05 \\
9\end{array}$ & 4635.752 & 2.593 & 2.86 \\
\hline Kangan & 366.056 & 737.849 & 0.417 & 0.46 \\
\hline $\begin{array}{c}\text { Yazd } \\
\text { Zanbagj }\end{array}$ & 54.772 & 165.932 & 0.091 & 0.10 \\
\hline Yaz Gas & 112.845 & 320.000 & 0.181 & 0.20 \\
\hline Yazd C.C. & 259.429 & 984.620 & 0.553 & 0.61 \\
\hline $\begin{array}{l}\text { Kerman } \\
\text { C.C. }\end{array}$ & $\begin{array}{c}1212.93 \\
7\end{array}$ & 4582.592 & 2.566 & 2.83 \\
\hline $\begin{array}{c}\text { Bandarabaa } \\
\text { sl }\end{array}$ & 30.212 & 28.575 & 0.018 & 0.02 \\
\hline $\begin{array}{l}\text { Abadan } \\
\text { C.C. }\end{array}$ & 608.535 & 2049.709 & 1.151 & 1.27 \\
\hline $\begin{array}{l}\text { Damavand } \\
\text { C.C. }\end{array}$ & 376.402 & 1235.436 & 0.689 & 0.76 \\
\hline Hormozgan & 361.885 & 1191.383 & 0.671 & 0.74 \\
\hline Total & $\begin{array}{c}7233.04 \\
9\end{array}$ & $\begin{array}{c}24314.28 \\
2\end{array}$ & $\begin{array}{c}13.62 \\
8\end{array}$ & 15.03 \\
\hline
\end{tabular}


Table III. Technical efficiency of every DMU

\begin{tabular}{|c|c|}
\hline DMUs Name & Technical Efficiency \\
\hline Orumieh & 0.944083273 \\
\hline Damavand C. C. & 0.986352737 \\
\hline Bandarabaas & 0.861045489 \\
\hline Tabriz & 0.936307242 \\
\hline Abadan C. C. & 0.982792057 \\
\hline Kerman C. C. & 0.999150320 \\
\hline Yazd C. C. & 1.000000000 \\
\hline Rey & 0.969413832 \\
\hline Zargan & 0.982197316 \\
\hline Shariati & 0.979404488 \\
\hline Shahid Salimi & 0.091045663 \\
\hline Shiraz & 0.965424598 \\
\hline Shirvan & 0.990300243 \\
\hline Sufian & 0.948030348 \\
\hline Kazerun & 0.984437241 \\
\hline Kangan & 0.959718352 \\
\hline Loshan & 0.991704841 \\
\hline Mashhad & 0.957628284 \\
\hline Hormozgan & 0.978253291 \\
\hline Hasa & 1.000000000 \\
\hline Yazd Gas & 0.958923065 \\
\hline Yazd Zanbagj & 1.000000000 \\
\hline
\end{tabular}

\section{F $\quad$ Primal and Dual model of DEA}

As it is shown in (1), the primal model of DEA is complicated and has fractional parts which make it difficult to solve but the dual model of DEA is easier to solve and its results are shadow prices of our variables that could be used as coefficient of goal programming model. In other word the dual model is suitable to solve and use.

\section{G Solving the dual model}

Dual amount are shadow prices or equitably prices in other word they are cost of producing one unit more than desired right hand side numbers (table VI). In fact these shadow prices are used for equitably pricing in various industries like electricity industry. The highest shadow price is belonging to efficient unit that for most equitable condition for the lowest demolition cost we used it as coefficient of goal programming function.

"Hasa" is the efficient unit which holds variables of dual model or coefficient of primal model:

$\mathrm{P}_{1}=71.2254$

$\mathrm{P}_{2}=29.6873$

$\mathrm{P}_{3}=3.1266$

In result the goal programming model is as (4).

$$
\begin{aligned}
& \text { Min } \begin{array}{l}
71.2254 S_{3}{ }^{+}+29.6873 S_{1}{ }^{+} \\
+3.1266\left(S_{2}{ }^{-}+S_{4}^{+}\right)
\end{array} \\
& \text {subjected to } \\
& x_{1}-S_{1}^{+}+S_{1}{ }^{-}=90.672668 \times 10^{6} \text { ton } \\
& x_{2}+S_{2}{ }^{-}-S_{2}{ }^{+}=10^{12} \quad k w h \\
& y_{1}-S_{3}{ }^{+}+S_{3}{ }^{-}=885 \times 10^{6} \mathrm{~m}^{3} \\
& x_{1}+x_{2}=y_{1} \\
& U-S_{4}^{+}=35548.9 \quad \$
\end{aligned}
$$

\section{Solve the GP Model}

Attending to described goals and their relation with goal model variables:

1. Minimizes the deviation of first goal $\left(71.2254 \mathrm{~S}_{3}{ }^{+}\right)$

2. Minimizes the deviation of third goal $\left(29.6873 \mathrm{~S}_{1}^{+}\right)$

3. Minimizes the deviation of second and forth goal $\left(3.1266\left(\mathrm{~S}_{2}^{-}+\mathrm{S}_{4}^{+}\right)\right)$

To solve the model Lingo Program is employed.

\section{CONCLUSION}

Model is attempted to minimize the cost and shows that a new management approach is vital and with replacing the clean fuel the demolition cost decrease. According to the model results, "Hasa" is rated efficient unit, although there are some other indicators to refer to, such as environmental and technical factors, age of machines, primary investment, repair and maintenance expenses, and efficiency of process, etc that could be considered for future papers and required to develop the model to compass the new and acceptable factors.

For further works it could be convenient to consider on replacing fuel, which needs an expert. And focusing on altering demolition and other harmful cost to profit is appropriate.

\section{References}

[1] R. Ramanathan, "Combining indicators of energy consumption and CO2 emissions: a cross-country comparison” Int J Global Energy Issues, 17(3):214-27, 2002.

[2] Tien Pao Hsiao, "Comparing Linear and Nonlinear Forecasts for Taiwan's Electricity Consumption”, Department of Management Science, Energy 31 (2006) 2129-2141, 2006.

[3] A. Charnes, W.W. Cooper, A.Y. Lewin, L.M. Seiford, "Data Envelopment Analysis: Theory, methodology and applications”, European Journal of Operational Research, Volume 98, Issue 2, Pages 250268, 1997.

[4] Brian Norton, Phillip C. Eames, and Steve N. G. Lo, "Full Energy Chain Analysis of Greenhouse Gas Emissions for Solar Thermal Electric Power, Generation Systems”, Renewable Energy I5 (I 998) 13 I I 36, 1998. [5] Jane H. Turnbull, "Greenhouse Gas Emission Reduction Associated with Livestock Waste Management Systems: A Case Study for the Langerwerf Dairy Waste Management System”. 
Table IV- Dual quantity of DEA model

\begin{tabular}{|c|c|c|c|}
\hline DMUs Name & Fuel $\left(\mathrm{Mm}^{3}\right)$ & $\mathrm{CO}_{2}$ & Net Production \\
\hline Shiraz & 0.1735 & 0.0371 & 0 \\
\hline Mashhad & 0.1927 & 0.0412 & 0 \\
\hline Loshan & 0.2471 & 0.2611 & 0 \\
\hline Rey & 0.0444 & 0.0095 & $-6.9 \mathrm{E}-18$ \\
\hline Tabriz & 209115 & 0.6221 & 0 \\
\hline Zargan & 0.4570 & 0.0977 & 0 \\
\hline Orumieh & 0.6335 & 0.6697 & 0 \\
\hline Shirvan & 0.7279 & 0.1555 & 0 \\
\hline Shariati & 0.7941 & 0.1696 & $-1.11 \mathrm{E}-16$ \\
\hline Sufian & 0.4945 & 0.5227 & $2.22 \mathrm{E}-16$ \\
\hline Hasa & 71.2255 & 296787 & 3.1266 \\
\hline Shahid Salimi & 0.0656 & 0.0694 & $-2.7 \mathrm{E}-17$ \\
\hline Kazerun & 0.0156 & 0.0164 & 0 \\
\hline Kangan & 0.1885 & 0.0402 & $-2.78 \mathrm{E}-17$ \\
\hline Yazd Zanbagh & 0.8734 & 0.1866 & $-1.11 \mathrm{E}-16$ \\
\hline Yazd Gas & 0.4343 & 0.0928 & 0 \\
\hline Yazd C.C. & 0.0742 & 0.0784 & 0 \\
\hline Kerman C.C. & 0.0160 & 0.0168 & 0 \\
\hline Bandarabass & $2.3 \mathrm{E}-27$ & 0.0540 & $6.13 \mathrm{E}+231$ \\
\hline Abadan C.C. & 0.0351 & 0.0371 & 0 \\
\hline Damavand C.C. & 0.0585 & 0.0618 & $2.78 \mathrm{E}-17$ \\
\hline Hormozgan & 0.0602 & 0.0636 & $2.78 \mathrm{E}-17$ \\
\hline
\end{tabular}

